\title{
Test to failure of a steel truss bridge - Calibration of assessment methods
}

\author{
T. Blanksvärd, J. Häggström, J. Nilimaa, N. Sabourova, N. Grip, B. Täljsten \& L. Elfgren \\ Luleå University of Technology, Sweden
}

\author{
A. Carolin \& B. Paulsson \\ Trafikverket, Luleå \& Borlänge, Sweden \\ Y. Tu \\ Southeast University, Nanjing, PR China \& Luleå University of Technology, Sweden
}

\begin{abstract}
The steel truss railway bridge at Åby River was built in 1957 with a span of $32 \mathrm{~m}$ (105 feet). In 2012 it was replaced by a new steel beam bridge and the old bridge was placed beside the river. It was tested to failure to study its remaining load-carrying capacity in September 2013. The test was carried out by Luleå University of Technology bycommission from Trafikverket as a part of the European Research Project MAINLINE (www.mainline-project.eu).In this paper some preliminary results are given. Two hydraulic jacks, anchored by cables to the bedrock, pulled the bridge downwards. The bridge remained elastic up to about three times the original design load and the load could then be almost doubled with substantial yielding deformations before a buckling failure appeared in the top girders for a load of ca. $11 \mathrm{MN}$ (1000 short tons) for a midpoint deflection of ca. 0, $2 \mathrm{~m}$ (8 inches). No brittle or fatigue failure in any of the joints appeared and the bridge proved to behave in a ductile way with a substantial hidden capacity.
\end{abstract}

\section{INTRODUCTION}

\subsection{General}

Growth in demand for rail transportation across Europe is predicted to continue. Much of this growth will have to be accommodated on existing lines that contain old infrastructure. This demand will increase both the rate of deterioration of these elderly assets and the need for shorter line closures for maintenance or renewal interventions. The impact of these interventions must be minimized and will also need to take into account lower economic and environmental impacts. New interventions will need to be developed along with additional tools to inform decision makers about the economic and environmental consequences of various intervention options being considered.

\subsection{MAINLINE}

The project MAINLINE, 2013, addresses the questions mentioned in the introduction through a series of linked work packages that will target a reduced environmental footprint in terms of embodied carbon and other environmental benefits. The project will:

- Apply new technologies to extend the life of elderly infrastructure (Work Package 1), Casas et al, 2013, see Elfgren et al. 2013, 2014.
- Improve degradation and structural models to develop more realistic life cycle cost and safety models (Work Package 2), see Chryssanthopoulos et al., 2013.

- Investigate new construction methods for the replacement of obsolete infrastructure (Work Package 3), see Schewe et al., 2013.

- Investigate monitoring techniques to complement or replace existing examination techniques (Work Package 4), see Bharadwaj et al., 2013.

- Develop management tools to assess whole life environmental and economic impact (Work Package 5), see Castlo et al., 2013.

The project consortium includes leading railways, contractors, consultants and researchers from across Europe, including Eastern Europe and the emerging economies. Partners also bring experience on approaches used in other industry sectors which have relevance to the rail sector. Project benefits will come from keeping existing infrastructure in service through the application of technologies and interventions based on life cycle considerations. Although MAINLINE will focus on certain asset types, the management tools developed will be applicable across a broader asset base.

This paper presents some of the work in Work Package 1 concerning bridges. Preliminary results are presented from a full scale test to failure in September 2013 of 50 year old steel truss bridge. 


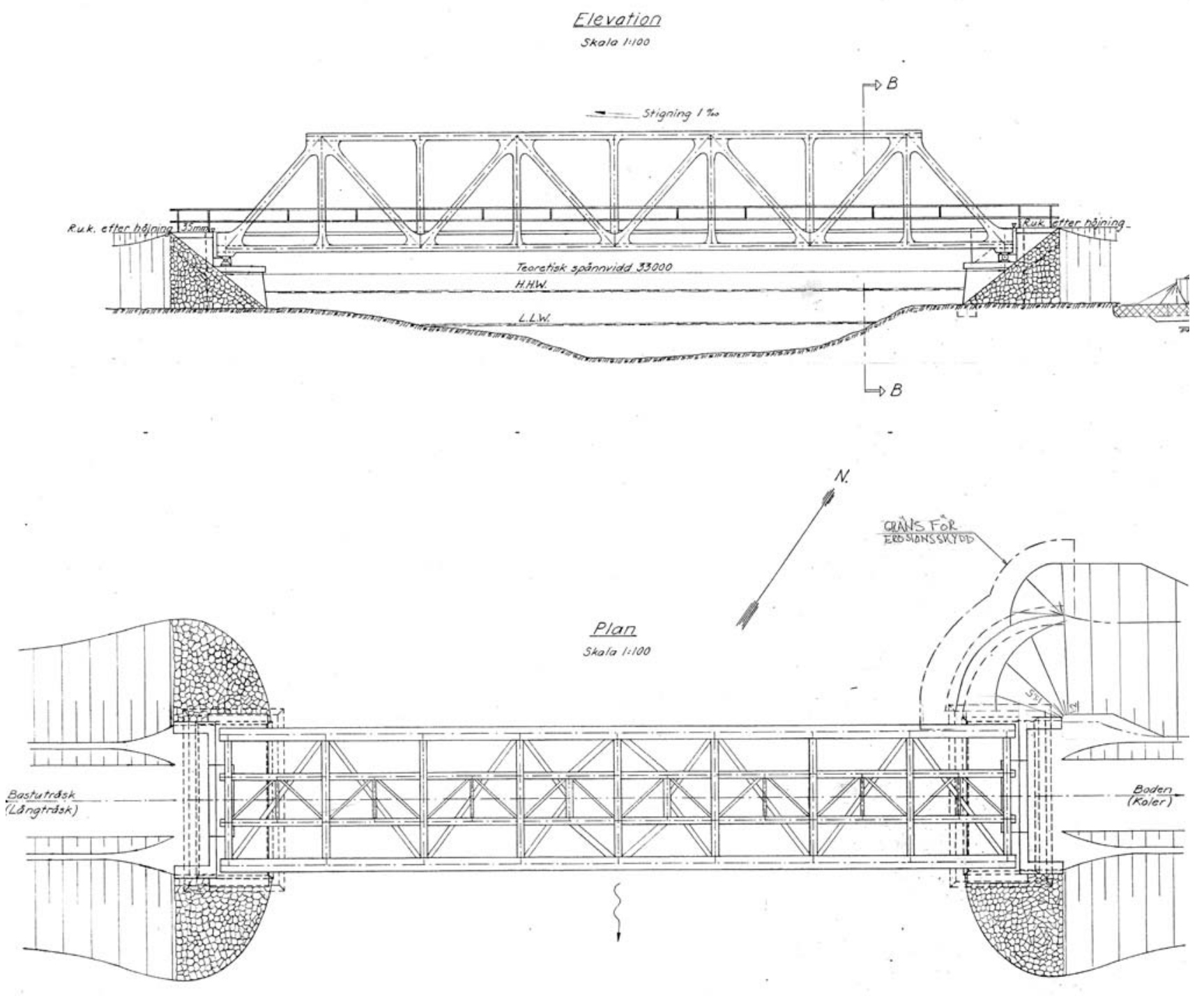

Figure 1. Elevation and Plan. Original drawing from 1957 of the Åby Bridge, span length 33 m. No 3500-1940-1, km 1049+50.

\section{DESIGN AND GEOMETRY}

The tested bridge has been carrying the Swedish northernmainline from Stockholm over the river Åby some $80 \mathrm{~km} \mathrm{SW}$ of Luleå. The line was originally built in 1894 and the now tested steel truss was designed and constructed in 1957, see Figure 1. The span has a length of $33 \mathrm{~m}$ and a width of 5,5 $\mathrm{m}$ The SW support has four pins while the NE support has four rollers. The supports are founded on moraine. An axle load of $250 \mathrm{kN}$ was used for the design. The steel quality for the main beams was SIS 1411 (yield stress $f_{\mathrm{s}}=250-260 \mathrm{MPa}$; failure stress $f_{\mathrm{u}}=440$ $\mathrm{MPa})$. Verticals, diagonals and secondary beams had the quality SIS $1311\left(f_{\mathrm{s}}=200-220 \mathrm{MPa}\right.$ and $f_{\mathrm{u}}=370$ $\mathrm{MPa})$.

\section{PRELIMINARY ASSESSMENT}

\subsection{Traditional Analysis}

A traditional assessment of the remaining fatigue capacity of the bridge was carried out in 1994 according to Swedish codes. It was found that some of the joints connecting the longitudinal beams to the transverse beams had an accumulated PalmgrenMiner sum higher than 20, which indicated that a fatigue failure was already overdue. However, no fatigue cracks could be seen when the bridge was inspected.

\subsection{Finite Element Model}

A first FEM analysis was carried out in 2012 for a quarter of the bridge assuming symmetry in two directions. Four node shell elements were used with 43000 nodes, Blanksvärd 2012. Several joints were 
encountered with von Mises stresses in the order of $100 \mathrm{MPa}$

\section{MONITORING}

\subsection{Bridge in original position}

Some 40 strain gauges, 10 deflection gauges and 3 temperature sensors were mounted on the bridge during the summer of 2012 in order to check strains and deformations in critical sections, Blanksvärd, 2013. The highest strains observed when ordinary trains passed over the bridge were of the order of $250 \times 10^{-6}$ corresponding to a stress of $50 \mathrm{MPa}$.

\subsection{Bridge in new position}

In the fall of 2012 the bridge was replaced by a new ballasted steel beam bridge and the old one was moved from the Åby river to a site parallel to the railway line. Here new tests were performed during 2013 both regarding static and dynamic conditions, Andersson\& Grip, 2013, according to the following plan:

(1) The bridge was instrumented with accelerometers in different setups and subjected to acontrolled force with variable frequency using a load shaker. Some accelerometers servedas reference at fixed position throughout all setups while others were moved to differentpositions. The output consisted of estimation of natural frequencies, mode shapes,damping ratios and frequency response functions. The results will serve as input forupdating numerical models.

(2) Based on design and capacity assessments, secondary systems as stringer beams andtransverse beams often give in large dynamic amplification factors. Both a stringer beamand a cross beam was instrumented with several accelerometers and excited using the loadshaker as part of the load scheme for (1). Since the natural frequencies of the secondarysystem were likely to be much higher than can be obtained by the load shaker, additionaltests with transient loading were performed.

(3) Damage detection- A local damage was introduced on a stringer beam and a transverse beam at a location that was notcritical for the later static load tests. The same setup as for (2) was used and measurements were performed with both the load shaker and transient loading. The aim was to determineif a localized damage on the bridge could be detected and how large this damage needed tobe. Part (2) served as input for the undamaged structure.

\section{UPDATED FINITE ELEMENT MODEL}

\subsection{Abacus}

In the spring of 2013 an updated FE model was designed by YongmingTu using Abaqus shell ele- ments, see Figure 2. The strain-stress relationship for the structural steel is considered as bi-linear with a hardening modulus $(\mathrm{H})$ in the second part of the curve.

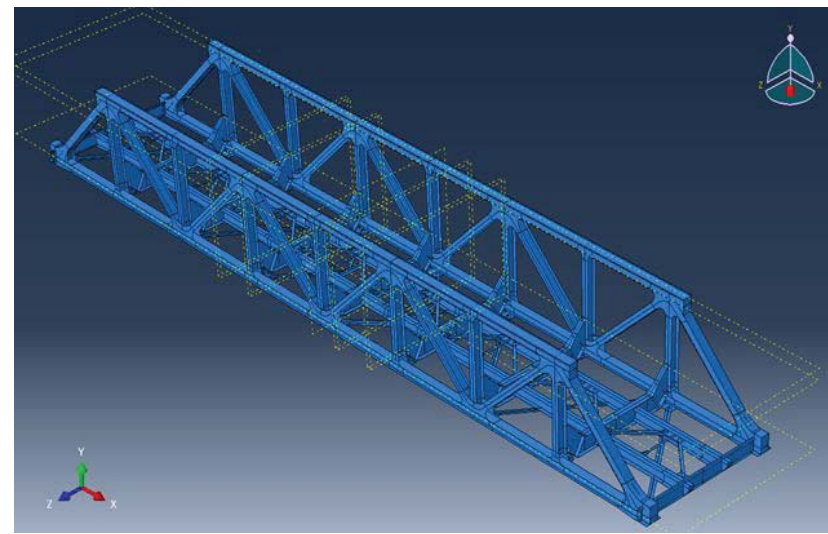

Figure 2. Enhanced FEM Model

A result from the model is given in Figure 3, where the first Eigenmode in bending with $\mathrm{f}_{1}=3,71$ $\mathrm{Hz}$ is compared to the measured value $3,67 \mathrm{~Hz}$.
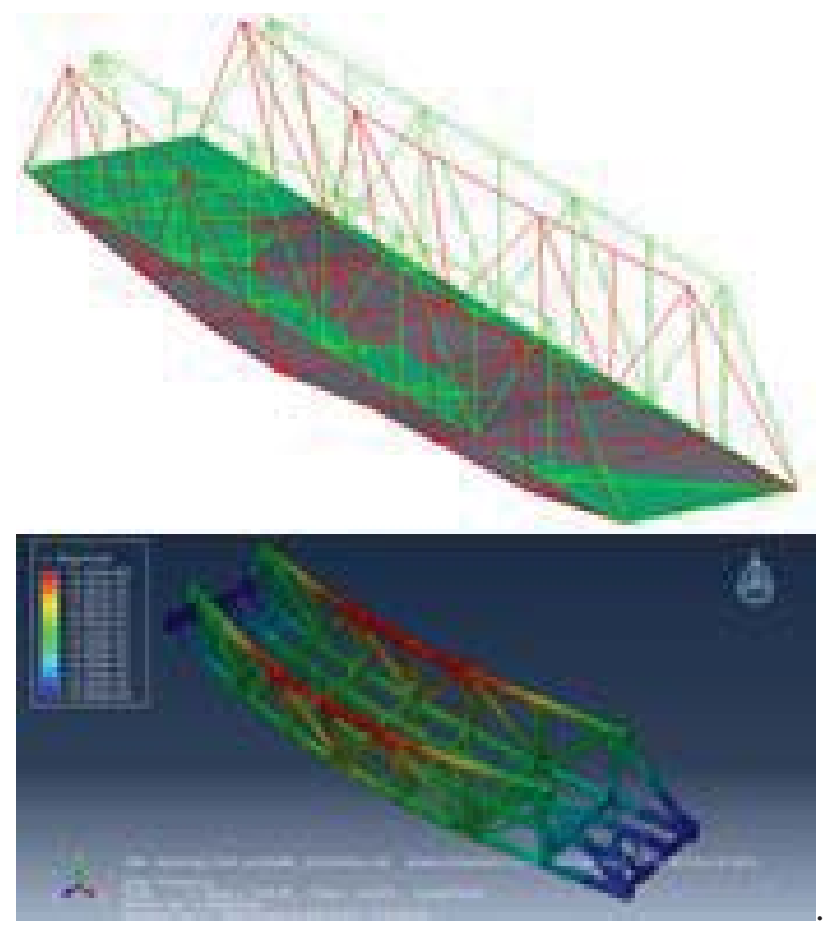

Figure 3. Measured (top) and modeled (bottom) first Eigenmode with frequencies of $3,67 \mathrm{~Hz}$ and $3,71 \mathrm{~Hz}$ respectively

\subsection{Reliability analysis}

The model was used to predict the ultimate load of the bridge with a reliability analysis where some of the given parameters were varied, Cremona, 2011, Casas et al., 2013 and Ghosn et al., 2013.In order to 
take into account the complex non-linear behavior of this bridge, the proposed FE model is also very complex and needs an important time for one nonlinear analysis. Trying to reduce the computing time and simplify as much as possible the assessment, the number of simulations to characterize the non-linear behavior of the bridge from a probabilistic approach must be reduced to a minimum. The number of simulations is highly dependent on the number of variables considered as random. For this reason, the preselection of the variables to be considered as random was performed considering some previous knowledge and engineering judgment. The variables that describe the geometry were considered as deterministic. Also the variability of elasticity modulus was considered to be small and negligible.

The random variables considered were the yielding strength and the hardening slope (hardening modulus) of the structural steel. The elasticity modulus was considered deterministic with a value equal to $210 \mathrm{GPa}$ and a total correlation is assumed between the yielding strength and the ultimate strength, taking the last one as 1.636 times the value of the yielding stress. The value 1.636 is the ratio between the ultimate and yielding strengths (360 over 220) considered in the design. With all these values defined and according to the bilinear shape of the curve, once the hardening modulus is defined, also the ultimate strain can be obtained, completing in this way the full stress-strain relationship

The following actions were considered in the analysis: self-weight of the structure, additional permanent loads and live load on the railway track including impact (UIC train load model).

Two results are presented in Figure 4, giving differentmaximum capacities, 5,4 MN for $f_{\mathrm{y}}=168 \mathrm{MPa}$ (top), and 7,8 MNfor $f_{\mathrm{y}}=256 \mathrm{MPa}$ (bottom)

\section{LOAD TO FAILURE}

\subsection{Loading procedure}

The load was applied by two jacks that pulled the bridge downwards. The jacks were anchored to the underlying bedrock by two injected cables. Several test runs were made with different maximum loads in order to monitor strains and deflections under different conditions. The final test to failure took place on Thursday, September 12, 2013.A preliminary load-deformation graph is given in Figure 5. The loads are based on readings from the oil pressure and some of the peaks do not reflect actual loads on the bridge. Instead they indicate that the jacks had run to the bottom and that a new grip had to be taken, Figure 6.
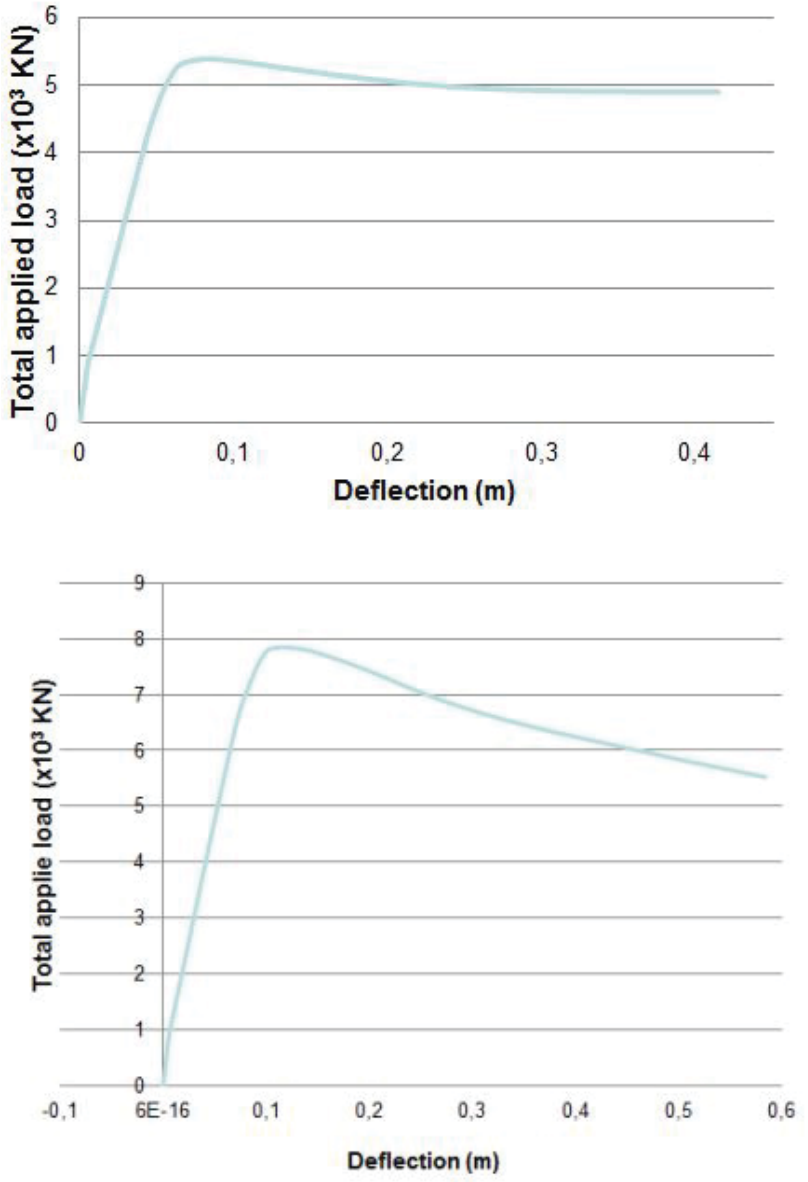

Figure 4. Predicted load-deflection diagrams for two simulations of the steel yield stress $f_{\mathrm{y}}=168$ MPagiving 5,4 MN (top) and $f_{\mathrm{y}}=256 \mathrm{MPa}$ giving 7,8 $\mathrm{MN}$ (bottom), Casas et al., 2013.

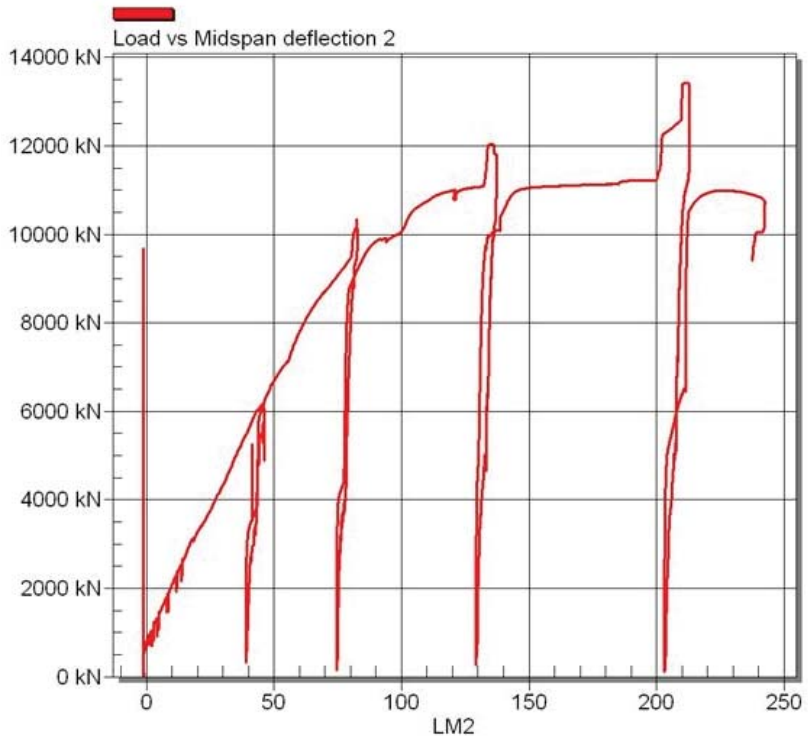

Figure 5. Preliminary load-deflection diagram from the final test to failure indicating a maximum load of $11 \mathrm{MN}$ for a midpoint deflection of ca $0,2 \mathrm{~m}$. 


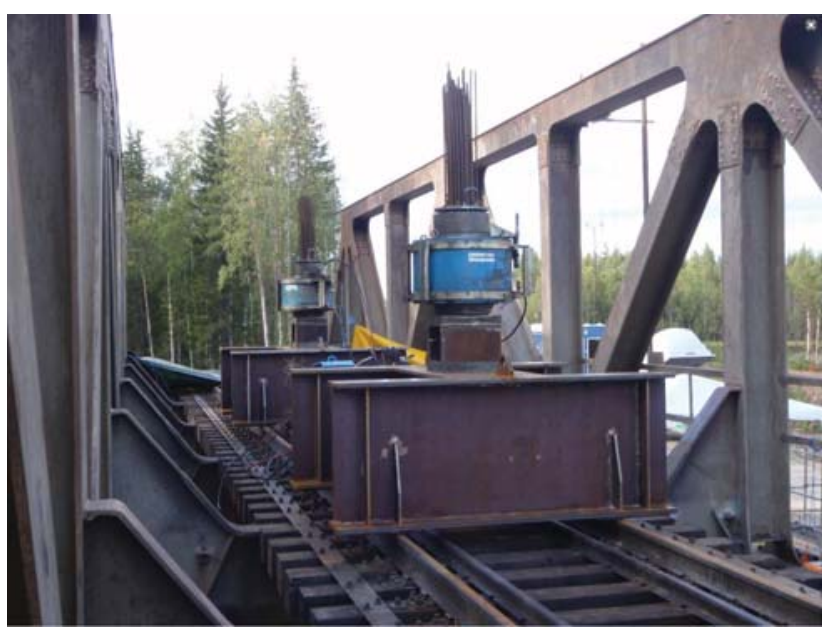

Figure 6. Load arrangement

\subsection{Observations}

Yielding in the steel started at a load of $8 \mathrm{MN}$ and buckling of the top girders appeared at about 11 $\mathrm{MN}$. The buckling failure was predicted by the enhanced FE model as can be seen from Figures 7 and 8

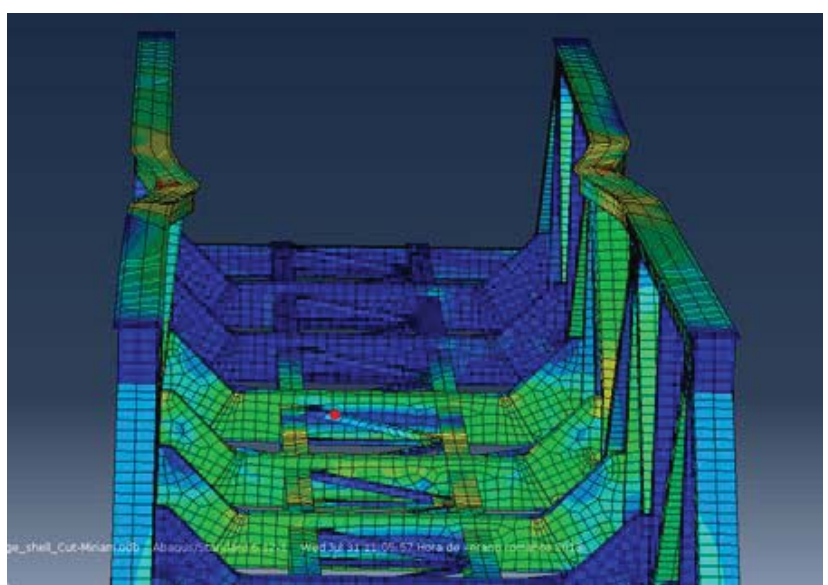

Figure 7. Predicted buckling failure in top girders, Casas et al., 2013.

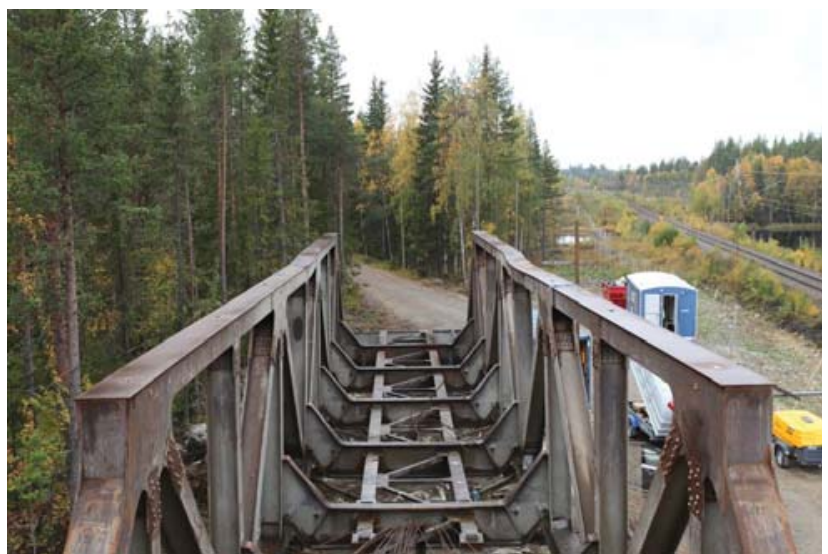

Figure 8. Actual buckling failure in top girders.
At the maximum load, extensive yielding could also be noticed in the bottom longitudinal girder, see Figure 9.

A relevant question is if the bridge could have been strengthened to obtain still a higher load as has be done for concrete bridges see e.g. Täljsten et al. 1994, 2006, 2011, Carolin, 2003, Blanksvärd, 2009, Sas, 2011 \& Puurula et al., 2012, 2013. This question was studied in the EU Project Sustainable Bridges, 2007, and a full scale test to failure was there performed on a reinforced concrete trough railway bridge, SB-7.3, 2008 \& Puurula, 2012.

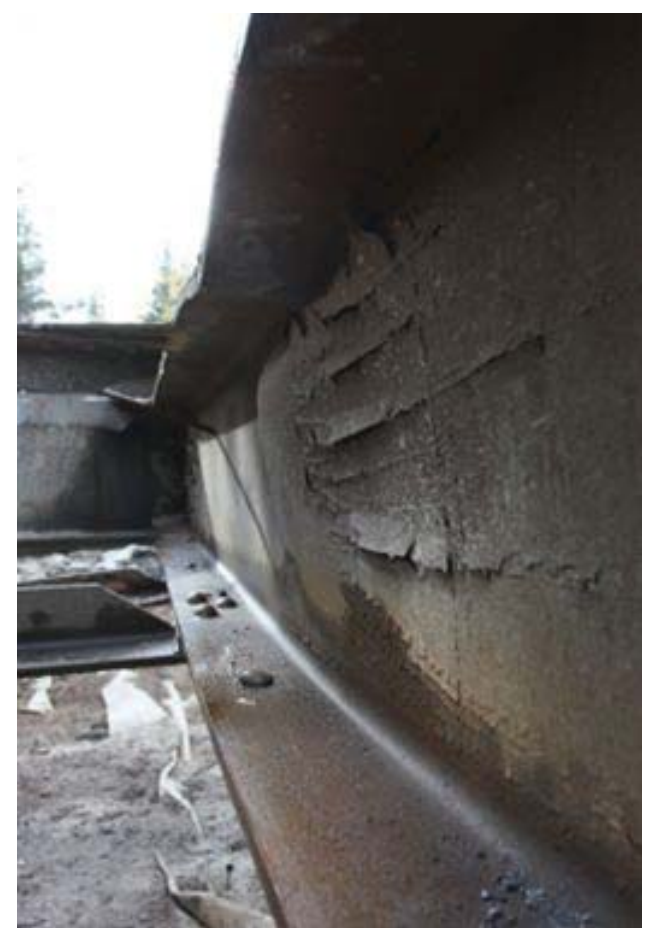

Figure 9. Yielding in the bottom longitudinal girders indicated by flaking off of corroded skin

\section{PRELIMINARY CONCLUSIONS}

The bridge remained elastic up to about three times the original design load and the load could then be almost doubled with substantial yielding deformations before a buckling failure appeared in the top girders for a load of $11 \mathrm{MN}$ (1000 short tons) for a midpoint deflection of ca. $0,2 \mathrm{~m}$ ( 8 inches). No brittle or fatigue failure in any of the joints appeared and the bridge proved to behave in a ductile way with a substantial hidden capacity.

The data will now be further analyzed in order to try to draw conclusions regarding assessment and strengthening methods for steel truss bridges. 


\section{ACKNOWLEDGEMENTS}

The authors gratefully acknowledge the European Union for funding the research project MAINLINE andTrafikverket, LKAB AB, HjalmarLundbohm Research Centre, HLRC, and the Swedish Fund for Construction Research, SBUF for additional funding. Furthermore the following individualshave taken an active part in the project:

- Lars Åström, Mats Petersson, Thomas Forsberg, Roger Lindmark \&Håkan Johansson,Complab, LTU. - Patrik Larsson, Site Manager, LTU.

- Peter Collin, Milan Veljkovic, Mikael Möller, Steel Structures, LTU.

- Andreas Andersson, Stefan Trillkott\&Claes Kullberg, Royal InstituteofTechnology, KTH, Stockholm.

JaroslawZwolski\&WladyslawCzyrnski, Wroclaw University, Poland.

- Julia Elhag, MSc student \&MhammedSalih Mohammed Mahal,PhD student, LTU.

\section{REFERENCES}

Andersson, A. \& Grip, N. 2013 Railway Bridge over Åbyälv. Instrumentation programme for dynamic testing. Royal Institute of Technology, Stockholm, 30pp.

Bharadwaj, U. et al. 2012.Report on assessment of current monitoring and examination practices in relation to degradation models.Mainline Deliverable D4.1, 84 pp. http://mainline-project.eu.

Blanksvärd, Thomas. 2009. Strengthening of concrete structures by the use of mineral based composites: system and design models for flexure and shear. Doctoral Thesis. Luleå University of Technology, ISBN 978-91-86233-23-5, 156 pp.

Blanksvärd, Thomas. 2012, MätprogramförbroarnaöverÅbyälvochRautasjokk (Program for measurements on the Åby and Rautasjokk bridges. In Swedish). Luleå University of Technology, Preliminary Report, $59 \mathrm{pp}$

Blanksvärd,

Thomas.

2013.MätprogramförbroarnaöverÅbyälvochRautasjokk, Fas 2 (Program for measurements on the Åby and Rautasjokk bridges, Phase 2. In Swedish). Luleå University of Technology, Preliminary Report, 75 pp

Carolin, Anders. 2003. Carbon Fibre Reinforced Polymers for Strengthening of Structural Elements.Doctoral Thesis 2003:18, Div. of Structural Engineering, Luleå University of Technology, $194 \quad$ pp. http://pure.ltu.se/portal/files/151462/LTU-DT-0318-SE.pdf

Casas, J.R. et al. 2013. Assessment methods for elderly rail infrastructure, MAINLINE Deliverable 1.2.http://mainlineproject.eu/

Castlo, D. et al. 2013. Proposed methodology for a Life Cycle Assessment tool (LCAT).MAINLINE Deliverable 5.4, 169 $p p$.http://mainline-project.eu/

Chryssanthopoulos, M., et al. 2013. Degradation and intervention modelling techniques. Mainline Deliverable D2.2, 184 pp. http://mainline-project.eu/

Cremona, Christian. 2011. Structural Performance. Probability based assessment. London and New York: ISTE-Wiley, 448 pp, ISBN 978-1-84821-236-7.
Elfgren, L. et al. 2013. Benchmark of new technologies to extend the life of elderly rail infrastructure. MAINLINE Deliverable 1.1.http://mainline-project.eu/

Elfgren, L. et al. 2014. Guideline for application of new technologies to extend the life of elderly rail infrastructure. MAINLINE Deliverable 1.4. To be published..http://mainline-project.eu/

Ghosn, Michael. \&Fiorillo, Graziano. 2013. Nonlinear Redundancy Analysis of Truss Bridges. Analysis Report. The City College of New York/CUNY, 23 pp.

MAINLINE, 2013.MAINtenance, renewaL and Improvement of rail transport iNfrastructure to reduce Economic and environmental impacts.A European Community $7^{\text {th }}$ Framework Program research project2011-2014 with 19 partners. Grant agreement 285121, SST.2011.5.2-6. Dr. Björn Paulsson, UIC/Trafikverket acts as Project Coordinator, see http//.mainline-project.eu

Puurula, Arto. 2012.Load-carrying capacity of a strengthened reinforced concrete bridge. Non-linear finite element modeling of a test to failure. Assessment of train load capacity of a two span railway trough bridge in Örnsköldsvik strengthened with bars of Carbon Fibre Reinforced Polymers (CFRP). Doctoral Thesis, Div. of Structural Engineering, Luleå University of Technology,http://pure.ltu.se/portal/files/36697444/Arto_Puurula.pdf

Puurula, A, Enochsson, O, Sas, G, Blanksvärd, T, Ohlsson, U, Bernspång, L, Täljsten, B\& Elfgren, L., 2013, Loading to failure and 3D nonlinear FE modelling of a strengthened RC bridge.Structure \& Infrastructure Engineering. http://dx.doi.org/10.1080/15732479.2013.836546

Sas, Gabriel. 2011. FRP Shear Strengthening of Reinforced Concrete Beams. Doctoral Thesis. Luleå University of Technology,http://pure.ltu.se/portal/files/32725277/Gabriel_Sas_Ph D_Thesis.pdf

SB-7.3, 2008. Field test of a Concrete Bridge in Örnsköldsvik, Sweden. Report in the project Sustainable Bridges, 415 pp, www.sustainablebridges.net

Schewe, B. et al., 2013. Benchmark of production and replacement of railway infrastructure. Mainline Deliverable D3.1, 59 pp. http://mainline-project.eu.

Sustainable Bridges. 2007.Sustainable Bridges - Assessment for Future Traffic Demands and Longer Lives. A European FP 6 Integrated Research Project during 2003-2007with 32 partners. Four guidelines and 35 background documents are available at www.sustainablebridges.net

Täljsten, Björn. 1994. Plate Bonding. Strengthening of Existing Concrete Structures with Epoxy Bonded Plates of Steel or Fibre Reinforced Plastics. Doctoral thesis 1994:152D. Div. of Structural Engineering, Luleå University of Technology,2nd Ed 1994, 283 pp.

Täljsten, Björn. .2006. FRP Strengthening of Existing Concrete Structures. Design Guideline. Div. of Structural Engineering, Luleå University of Technology, ISBN 91-8958003-6, $1^{\text {st }}$ Ed 2002, $4^{\text {th }}$ Ed 2006, 228 pp.

Täljsten, B., Blanksvärd, T.\& Sas, G. 2012. Handbok för dimensionering i samband med förstärkning av betongkonstruktioner med pålimmade fiberkompositer (Design Guideline for FRP Strengtheningof Existing Concrete Structures. In Swedish). Div. of Structural Engineering, Luleå University of Technology. ISBN 978-917439-146-6, $184 \mathrm{pp}$. 